\title{
The Effect of Ethnic Diversity and Community Disadvantage on Social Cohesion: A Multi-Level Analysis of Social Capital and Interethnic Relations in UK Communities
}

\author{
James Laurence
}

A number of studies have found a negative relationship between ethnic diversity and social capital and assumed from this a harmful effect of diversity on social cohesion. This article suggests that social cohesion must be treated as a multifaceted concept and any analysis into the relationship between diversity and social capital needs to be complemented by an analysis of diversity's effect on 'relations between ethnic groups'. Our results show that while increasing diversity does have a negative impact on social capital, it simultaneously improves perceptions of, and relations between, ethnic groups.

Furthermore, we find that forming 'bridging' ties in diverse environments plays a significant role in the positive relationship between diversity and tolerance, and that the presence of 'bridging' ties can also reduce the negative impact of diversity on social capital. However, while our results show that diversity has both positive and negative effects on social cohesion, we find that it is disadvantage which has the most detrimental impact, undermining both social capital and interethnic relations. We also find evidence that using a more sensitive measure of diversity (creating an area typology based on the proportional size, number, and type of ethnic groups in an area) reveals that living in different structures of diversity may lead to different social cohesion outcomes.

\section{Introduction}

This article explores the relationship between ethnic diversity, socioeconomic disadvantage, and social cohesion in English communities by analysing the effect of ethnic heterogeneity on two core dimensions of social cohesion: 'social capital' and 'relations between ethnic groups'. Theoretically, diversity is posited to operate the same way (either positively or negatively) on social cohesion. However, the concept of social cohesion is multifaceted and, to our knowledge, there has been no research into whether diversity operates differently on different aspects of social cohesion, at the community level, within the same sample. This is a vital test as the relationship between diversity and social cohesion contains two seemingly conflicting 
theories: that increasing ethnic diversity undermines trust and social capital (Alesina and Ferrara, 2002; McLaren, 2003; Putnam, 2007), but that diversity can also improve relationships between ethnic groups (Stein et al., 2000; Oliver and Wong, 2003; Marschall and Stolle, 2004). While the former is predicated on diversity undermining the level of trust and connectedness in a community, the fact that diversity can improve relations between ethnic groups assumes social interaction and interethnic contact must occurring between different ethnic groups. However, these two theories may not be irreconcilable.

First, the posited negative effect of increasing heterogeneity on social capital may be correct in that higher diversity leads to a reduction in the total levels of network interconnectedness compared to what they would be in a homogeneous community. However, in diverse areas, what interaction and interconnectedness is occurring (although lower than in homogeneous communities) will more likely be interethnic in nature and thus drive improved interethnic relations. Therefore, we predict that while social capital will be lower in heterogeneous areas, due to an overall undermining of interconnectedness and interaction, tolerance to diversity will be greater. An important advantage of this paper is that we explore the effect of diversity on different dimensions of social cohesion 'amongst the same sample of individuals'.

Furthermore, we attempt to find evidence for our claim that what links community level diversity to individual level social cohesion outcomes is its effect on the connectedness (and the ethnic make-up) of an individual's social network. If it is the case that diversity undermines absolute levels of interconnectedness (leading to lower social capital) but increases the likelihood of interethnic contact (leading to higher tolerance) then, using a measure of the ethnic composition of one's social network, we would expect that 'bridging' ties will play a strong mediating role in the relationship between diversity and higher individual rates of tolerance, and also that an individual with 'bridging' ties will experience the negative effect of diversity less strongly, as they are more likely to have formed social connections in diverse communities, compared to those without.

Importantly, ethnically diverse areas also tend to be more disadvantaged. Disadvantage is posited to heighten perceptions of powerlessness and mistrust, undermining levels of interaction and thus lowering social capital. Disadvantage is also predicted to have a pejorative effect on interethnic relations, where competition for scarce resources can lead to 'interracial material competition' or 'social identity threat'.
Therefore it is vital we also explore how far the effect of diversity on social cohesion is dependent on the level of disadvantage in a community

Secondly, this article aims to remedy some of the problems with the measurement of diversity in previous research. Most studies explore the effect of diversity using a single diversity index. However, evidence suggests that different ethnic groups, as well as different ethnic mixes in a community, may have differential effects on social cohesion. To address this we experiment with using a new measure of diversity which utilizes cluster analysis to create an area typology, categorizing communities into distinct area types based on the proportional size, number, and type of ethnic groups in an area.

The main research questions of this paper can therefore be stated as follows: what is the effect of increasing ethnic diversity at the local level on reported levels of 'social capital' and 'relations between ethnic groups' (and what evidence can we find for the mechanisms at work)? To what extent is the observed effect of diversity dependent on the level of socioeconomic disadvantage? How far is the effect of diversity also dependent on the type, proportional size, and number of ethnic groups in a locality?

\section{Theoretical Framework}

\section{Social Capital and Social Cohesion}

Interest in the concept of social cohesion is rapidly increasing in both the academic literature, and public and policy discourse, in particular that of the relationship between social cohesion and ethnic diversity (Forrest and Kearns, 2001). We have also witnessed a rise in research into the relationship between social capital and diversity (Alesina and Ferrara, 2000; 2002; Costa and Kahn, 2003; Putnam, 2007; Letki, 2008). The result has been that " $[\mathrm{t}]$ he re-emergence of concerns with 'neighbourhood' and 'community' and the links to social cohesion are...enmeshed in a partial re-conceptualisation of these issues within more general debates around the concept of social capital" (Forrest and Kearns, 2001, p. 2137).

Social capital can be defined as "those features of social organization, such as trust, norms and networks that can improve the efficiency of society by facilitating coordinated actions" (Putnam, 1993, p. 167). It taps those "features of social life-networks, norms, and trust-that enable participants to act together more effectively to pursue shared objectives" (Putnam, 1995, p. 156). At the core of concepts of social capital are 
notions of interaction, social networks, and most importantly, their level of interconnectedness.

Social cohesion, however, is a much broader concept, generally referring to "a state of strong primary networks (like kinship and local voluntary organizations) at the communal level" (Lockwood, 1999, p. 69), capturing the extent of connectedness and solidarity in communities, "as characterized by a set of attitudes and norms that includes trust, a sense of belonging and the willingness to participate and help" (Kawachi and Berkman, 2000; Chan and Chan, 2006, p. 290). In recent years, it has been government and policy groups that have been at the forefront of exploring the concept of social cohesion. The UK Commission on Integration and Cohesion (COIC) (2007) propose that a cohesive community contains trust, a willingness to support one another, a sense of belonging, and importantly, a respect for differences.

What is striking about the concept of social cohesion is its theoretical similarities to social capital. Defining cohesion includes ideas such as common values, social order, social solidarity, place attachment, social networks, interaction, shared values, and associational activity (Jensen, 1998; Woolley, 1998; Kearns and Forrest, 2000; Forrest and Kearns, 2001; Chan et al., 2006), which all feature strongly in social capital definitions as well.

The result is that differentiating 'social cohesion' as a separate phenomenon to 'social capital' becomes difficult. Many of the variables suggested as measures of social cohesion, including membership of community and civic groups, how much people trust others, attachment to neighbourhoods, density of social ties, and levels of reciprocity, are also found as measurements of social capital. More recently, especially in relation to ethnic diversity, researchers have begun analysing levels of social capital as indicators of overall levels of social cohesion (Letki, 2008). Social cohesion therefore becomes less a uniquely measurable attribute and more an assumed product of areas with high levels of social capital. This assumes, however, that social capital is an unproblematic measure of social cohesion.

Chan et al. (2006) draw an important conceptual difference between the two concepts: while a community may have high levels of social capital, "high amounts of social capital need not imply a high level of social cohesion" (Chan et al., 2006, p. 292). Using Putnam's $(1993,2000)$ bridging and bonding dichotomy, highly ethnically segregated areas may have high levels of bonding capital but few interethnic ties at all. Depending on the sense of community and shared identity already present in an area, increasing diversity may, for example, foment a sense of threat to in-group identity if there exists a perceived possibility of "loss of status, or an absence of the possibility to improve low status". This "accentuates subgroup solidarity, sharpens intergroup boundaries, accentuates ethnocentric attitudes and behaviour... and produces a more focused and polarized ingroup prototype" (Hornsey and Hogg, 2000; p. 144). This may lead to a renewed growth in bonding capital and localized trust but very little 'bridging' capital. If social capital alone were used as a measure of social cohesion in an area, such communities may appear cohesive.

Hooghe et al. (2006; p.3) believe that measuring social cohesion can be improved by including measures of "minority-majority relations and... attitudes of acceptance or hostility" towards ethnically defined groups. Similarly, the COIC state one of the key conditions of cohesion is a "climate of mutual understanding and respect" between individuals of different backgrounds (2007; p. 7). This is important as "ethnocentrism, racism and other feelings of ethnic prejudice can be as detrimental for the maintenance of cohesion as the absence of ... trust" (Hooghe, 2003; p. 6).

At the same time, public and policy discourse on social cohesion in the United Kingdom has tended to focus primarily on the problematization of ethnic diversity, and in particular Muslim communities, for building social capital and cohesion (Robinson, 2005). Cheong et al. (2007) make the point that social capital itself is a politicized concept. They note that the current delineations between good ('bridging') and bad ('bonding') capital for cohesion are relative to the prevailing ideological climate. Strong kin ties (bonding) amongst Asian groups were once viewed as a useful resource for successful social integration (Rex and Tomlinson, 1979). Now, "bonding... especially amongst Asian Muslim groups...[is] seen as threatening solidarity and cohesion" (Cheong et al., 2007: 32). Taken as a whole, there is a "political discourse [that] prioritise[s] certain forms of cohesion (in particular, racial and religious) over others (such as gender and class)" (Flint and Robinson, 2008; p. 5). Such a bias is demonstrated in the use of Kearns and Forrest's (2000) 'five elements of social cohesion' in the government commissioned Cantle Report. While it emphasized their point on 'equality of opportunity', Kearns and Forrest's argument on the need to 'reduce wealth disparities' was omitted (Flint and Robinson, 2008).

The growing debate in both academic and governmental policy spheres therefore requires some refocusing. On the one hand, problems exist in conceiving of social cohesion as simply a product of high social capital, and there is a distinct need to incorporate aspects of interethnic relations and tolerance to diversity into measurements of cohesion. However, 
on the other hand, it is vital not to concentrate solely on the role of ethnic diversity, sidelining the role of disadvantage in undermining cohesion.

\section{Diversity and Disadvantage}

Theoretically, the effect of diversity on 'social cohesion' is divided into two perspectives: the 'contact hypothesis' and the 'threat hypothesis'. Contact theory suggests prejudice can be reduced, and cohesion increased, by equal status contact between groups co-operating in the pursuit of common goals and sanctioned by institutional support (Allport, 1954). According to the contact hypothesis, as diversity increases, the likelihood of interethnic bonds developing increases, which work to prevent negative perceptions and misinformation regarding other ethnic groups from becoming cemented (Gordon, 1964; Varshney, 2003). A recent meta-analytic test of intergroup contact theory by Pettigrew and Tropp (2006) finds strong evidence for Allport's claims that intergroup contact tends to reduce intergroup prejudice and state that "contact situations designed to meet Allport's optimal conditions achieved a markedly higher mean effect size" (Pettigrew and Tropp, 2006; p. 766).

The 'threat hypothesis' proposes that diversity may undermine cohesiveness within communities where formerly dominant groups come to feel threatened as increasing numbers of people from minority ethnic groups settle in their area. The central tenet of this theory is that members of the dominant group may come to feel that certain resources belong to them, and "when those resources are threatened by a minority group, members of the dominant group are likely to react with hostility" (LeVine and Campbell, 1972; Giles and Evans, 1986; McLaren, 2003; p. 915).

Recent research has produced mixed results. Studies from the United States on the effect of community context on attitudes have found that as diversity in a neighbourhood increases, hostility towards minority ethnic groups also increases (Taylor, 1998). Putnam (2007) found that increasing diversity not only undermined 'bridging' social capital but also 'bonding' social capital, leading to a 'hunkering down' (a form of social isolation) between all individuals in diverse communities. Alesina and Ferrara $(2000,2002)$ and Costa and Kahn (2003) found a strong, negative relationship between levels of social trust and racial diversity at the US state level, which they attribute, in part, to 'a natural aversion to heterogeneity' where "people distrust those that are dissimilar to themselves" (Alesina and Ferrara, 2000; p. 225). Such 'distrust of dissimilarity' however is likely effected by historical factors (for example whether an individual is a member of a group that historically has been discriminated against) (Alesina and Ferrara, 2000). Also, as McPherson et al. (2001; p. 420) note in their discussion of 'homophily', tendencies towards racegroup homogeneity also need to be understood in the context of "differences in racial/ethnic groups' positions on other dimensions (e.g. education, occupation, income, religion) and the personal prejudices that often result from the latter".

Overall, these results suggest that in diverse areas interactions between different groups occur infrequently and such lack of contact leads to lower levels of trust and reciprocity. However, a number of recent research findings disagree with these conclusions. Oliver and Wong (2003) found that diverse communities are associated with 'positive' attitudes towards individuals from other ethnic groups, while Bledsoe et al. (1995) found that Black people living in ethnically mixed communities are more likely to form interethnic friendships than those living in more homogeneous Black communities. Recent research from the United Kingdom has provided greater evidence to suggest diversity has a positive or neutral effect. Hewstone et al. (2005) examined attitudes between Protestants and Catholics in Northern Ireland and discovered that after controlling for class, education, and prior experience of integrated education, intergroup contact (the likelihood of which increased with increasing diversity) made a consistent, significant contribution to more positive attitudes towards intergroup members. Recent work by Letki (2008) in the United Kingdom found a diminished or vanishing negative effect of diversity on social capital when the detrimental effect of fewer socioeconomic resources is taken into account.

There is a much greater consensus in the literature on the negative role of socioeconomic deprivation. In terms of social capital, disadvantage has been shown to undermine an individual's willingness to interact or engage in socialization with neighbours, heightening perceptions of powerlessness and mistrust (Oliver and Wong, 2003; Marschall and Stolle, 2004; Li et al., 2005; Letki, 2008). In terms of interethnic relations, physical and economic disadvantage can encourage interracial material competition', where minority ethnic groups can be perceived as a threat to the majority population's position and/or as a competitor for scarce resources, fomenting negative attitudes towards members of other racial groups (Oliver and Mendelberg, 2000). That it is an empirical fact that poverty and disorder tend to be highly correlated with racial 
diversity (Sampson and Groves, 1989; Sampson et al., 1997), it is very important to try and partial out the relative effect of disadvantage in any analysis of diversity and social cohesion.

\section{Linking Community Context to Individual Outcomes}

There is therefore a considerable corpus of theory and a growing body of research into the relationship between ethnic diversity and social cohesion. However, how does the level of community ethnic diversity and disadvantage translate to individual level perceptual or behavioural outcomes which are relevant to our social capital and tolerance to diversity dimensions of social cohesion?

There are a number of theories based in sociopsychological research which examine the effect of ethnic diversity on the individual, and the individual as a member of a social group. These include: 'homophily' and the tendency to form bonds with those similar to oneself (McPherson et al., 2001); 'social identity theories', where co-habitation by different ethnic groups can stimulate a symbolic threat to a group's identity, resulting in the categorization of others as 'out groups' and an attempt to limit the "opportunities of other ethnic groups and their members" to achieve a sense of "positive group distinctiveness" (Tajfel and Turner, 1979; Hornsey and Hogg, 2000; Esses et al., 2001; p. 390); and also 'realistic group threat' theories where perceived threats to one's resources manifest themselves in negative stereotyping and a reinforcement of group boundaries (Campbell, 1965; Sherif, 1966).

Considering that at the heart of the idea of social capital is social connectedness, where the "multiplicity of interactions lead to the building of knowledgebased trust" (Falk and Kilpatrick, 2000; Marschall and Stolle, 2004; p. 146), then be it caused by a perceived symbolic threat, or threat to one's resources, or even a 'natural' tendency towards familiarity, increasing ethnic diversity may result in less absolute levels of interaction between individuals within a locale, retarding the development of community social networks, and in turn diminishing an individual's level of social capital (Alesina and Ferrara, 2000; p. 850; Costa and Kahn, 2003). Recent research by Stolle et al. (2008) found strong evidence for this, observing that engaging in interaction with one's neighbours strongly mediates the negative effect of diversity on trust.

Interaction also features prominently in the link between diversity and interethnic relations. As discussed, the "absence of direct contact with, or sustained knowledge about, individuals of different racial, ethnic or class backgrounds serves to reinforce prejudices" (Bobo, 1988; Stolle et al., 2008; p. 59). It is interaction therefore that can breakdown group boundaries between disparate ethnic groups, undermine negative stereotypes, and in turn aid in the cultivation of a 'superordinate identity' based on the inclusion of former outgroups (Stolle et al., 2008; Pettigrew and Tropp, 2000). While increasing community ethnic diversity can undermine an individual's stock of social capital by limiting the development of social networks in their neighbourhood, at the same time, living in a heterogeneous environment can increase the likelihood of contact between members of different ethnic groups which translates into improved individual tolerance to diversity. In sum, interaction and interethnic contact play a central role in the connection between community level diversity and individual level social cohesion outcomes.

\section{Limitations of Previous Research}

There are a number of methodological drawbacks in the diversity literature, one of the most important being the method of measuring diversity. Diversity is often treated either as an index (Alesina and Ferrara, 2000; 2002; Putnam, 2007; Letki, 2008), or by analysing the effect of rising percentages of a chosen ethnic group in an area, e.g. percent black (Oliver and Wong, 2003; Marschall and Stole, 2004; Putnam, 2007). These result in a number of problems in the analysis.

First, diversity indices make the assumption that all ethnic groups have a similar effect on cohesion in communities (Hooghe et al., 2006; Putnam, 2007). However, analysis of the 2008 British Social Attitudes Survey $^{1}$ shows significant differences exist in how positively or negatively different ethnic groups view one another (measured using 'feeling thermometer' scores). Such differential patterns of acceptance are likely to have a significant effect on neighbourhood cohesion depending on which groups co-habit an area.

Secondly, the most commonly used diversity measures (indices of fractionalization, indices of segregation, the percentage of an area's population who are members of a particular ethnic group) essentially divide communities on a unidimensional homogeneity-heterogeneity continuum i.e. on a single scale of homogeneous to mixed. However, a number of recent comparative pieces of research on the propensity for ethnic conflict suggest such a treatment of diversity may not effectively capture the function diversity plays in conflict situations. These have focused on the roles 
of ethnic fractionalisation and ethnic polarization in the incidence of interethnic violence (Easterly and Levine, 1997; Montalvo and Reynal-Querol 2005a; 2005b), exploring the possibility that propensity for conflict is greater not with increasing heterogeneity but where there are two highly ethnically bifurcated populations; a situation an index of heterogeneity would not be sensitive enough to pick up. Recent research in urban social segregation has begun trying to capture the multidimensionality of diversity in communities by creating area typologies that categorize communities based on the proportional size, the number, and the type of ethnic groups in an area (Poulsen et al., 2001; Forrest et al., 2003; Johnston et al., 2003; Rawlings et al., 2004; Turner and Fenderson, 2005).

How might these different constellations of diversity translate into differential patterns of social cohesion at the individual level? Firstly, in terms of the existence of different degrees of animosity towards certain ethnic groups, we would expect that areas containing high concentrations of groups viewed particularly negatively would experience significantly less community-wide interaction (due to stronger intra-group boundaries and greater out-group prejudice) resulting in lower reported levels of social capital. Furthermore, greater animosity between groups is also likely to result (both as a consequence of such pejorative perceptions, and also from poorer rates of interaction between community members) in lower reported levels of tolerance within the community, relative to areas containing greater concentrations of ethnic groups viewed more positively.

Secondly, in terms of whether the number and size of ethnic groups in an area foment differential propensities to conflict: trust and interaction will more likely be undermined in areas where perceived threat is greater (whether living in ethnically mixed or bifurcated areas are more likely to strengthen in-group boundaries and out-group prejudice), while greater perceptions of threat (along with its antecedent weaker patterns of interaction and network interconnectedness) are also likely to undermine tolerance to diversity. Another possibility is that ethnically bifurcated areas (compared to more ethnically mixed areas), where there are larger concentrations of a smaller number of ethnic groups, may report higher social capital due to co-habitation with a larger stock of one's own ethnic group (and potentially higher rates of interaction), but conversely, lower tolerance due to less exposure to members of other ethnic groups. We will therefore explore whether different structures of diversity lead to different individual level social cohesion outcomes.

\section{Methodology and Measures}

Our study utilizes the 2005 UK Citizenship Survey, the 2001 UK Census, and the 2004 Indices of Deprivation. All individual level dependent and independent variables were obtained from the 2005 Citizenship Survey. The community level diversity and residential turnover variables are from the 2001 U.K. Census, and the measure of community disadvantage is based on the 2004 Index of Multiple Deprivation. All three sets of data were used simultaneously in the modelling ${ }^{2}$.

To capture the local-level mechanisms that theoretically connect diversity to an individual's reported social capital and tolerance we use Middle Super Output Areas (MSOAs) as the measurement of an individual's locality. MSOAs are statistical areas defined by the Office for National Statistics (ONS) with a minimum population of 5,000 residents and an average population of 7,200 .

\section{Social Cohesion}

Social cohesion is measured by examining two of its core aspects: social capital and interethnic relations. In terms of social capital, we follow Putnam (2007) in adhering to "a 'lean and mean' definition: social networks and the associated norms of reciprocity and trustworthiness" (137), which focuses on the "primary indicators of social capital (i.e. social trust, community attachment, and sociability)" (p. 155). To capture the aspect of trustworthiness we include the question: 'how much do you trust people in your neighbourhood?' We include two questions to capture norms of reciprocity. First, 'whether people in this neighbourhood are willing to help their neighbours' aims to capture perceptions of reciprocity between neighbours (Lochner et al., 2003) and 'how likely is it people in the neighbourhood would participate to solve community problems' aims to capture the willingness of neighbours to come together to solve local problems (Putnam, 2000). The final question, 'whether people in this neighbourhood share the same values', aims to capture the part of social capital that sees "individuals connected to one another through...common values" (Putnam, 2000; p. 312). Although the loading of this question is lower $(-0.571)$, it remains sufficiently high to include, and more importantly it is negatively coded, helping to mitigate 'acquiescence bias' (Weisberg, 2005). Factor analysis is used to create a composite measure of social capital and also a more sensitive measuring instrument (Blalock, 1970).

To measure the perceptions of, and tolerance towards, other ethnic groups we create an index 
using two questions: 'to what extent do you agree that this local area is a place where people from different backgrounds get along well together' ${ }^{3}$ and 'how far would you agree or disagree that people in this area respect ethnic differences'. These two questions aim to capture the aspects of: 'respect and tolerance for ethnic differences' and the 'state of interethnic relations' deemed essential for social cohesion (Chan et al., 2006; Hooghe et al., 2006; COIC, 2007) $)^{4}$.

\section{Community Level Determinants of Social Cohesion}

To capture the effect of diversity we will first use the Simpson Reciprocal Index of Diversity (Simpson, 1949) which amalgamates all ethnic groups into a single measure of 'the likelihood that any two individuals randomly selected from a given community will be from the same category'. We divided our populations into: White British, White Other, Asian Indian, Asian Pakistani, Asian Bangladeshi, Asian Other (including mixed White/Asian), Black (including Black Caribbean, Black African, Other Black, and mixed White/Black), Chinese, and Other (including mixed White/Other).

To test for the possibility that different patterns of community diversity may affect cohesion differently we develop a typology of areas based on the proportional size, number of ethnic groups, and type of ethnic group in a community. For this we first identified the main ethnic populations in England: 'White British', 'Asian Indian', 'Pakistani and Bangladeshi', 'Black' (including Black African and Black Caribbean), and 'born in Eastern Europe'. Due to their small sample size and ethnic and cultural similarities, Pakistani and Bangladeshi populations were amalgamated into one variable $^{5}$. The same applies to Black Caribbean and Black African populations because of the high correlation (0.70) between the two groups in terms of the communities in which they reside. The area types do not distinguish between different concentrations of the remaining ethnic groups (i.e. Chinese, Mixed Race, Other Black, Other Asian, and Other), as these populations are not in large enough concentrations to construct distinct categories.

To develop our area typologies we employ $k$-means cluster analysis. This tool groups areas with similar population profiles according to their ethnic population distribution in communities across England. As they are based on relative measures, their parameters are specific to the dataset being analysed. Table 1 shows the final cluster centres of the analysis.

The final clusters reflect a typology of areas based on their ethnic distributions. Area 1 contains predominantly White British residents and small numbers of non-white groups. Areas 2 and 6 define the two levels of ethnically mixed areas. Area 2 defines lesser-mixed areas that contain a substantial White British population and smaller but approximately equal numbers of other minority groups. Area 6 defines greater-mixed areas that have smaller numbers of White British and larger numbers of minority groups. Area 3 defines areas with a substantial White British population and a substantial Asian Indian population, Area 4 defines areas with substantial White British and substantial Pakistani and Bangladeshi populations, and Area 5 defines areas with substantial White British and substantial Black populations ${ }^{6}$.

The Index of Deprivation 2004 (ID 2004) is used to measure overall community levels of disadvantage ${ }^{7}$. We also include the rate of residential turnover (calculated by adding the inflow and the outflow of persons in an area) per 1,000 people, as research shows that there is a correlation between longevity of residence in an area and the maintenance of 'active social relationships' (Coulthard and Morgan, 2002; Travers et al., 2007).

Table 1 Final cluster centres for cluster analysis of ethnic groups

\begin{tabular}{|c|c|c|c|c|c|c|}
\hline & & & & & & \\
\hline & 1 & 2 & 3 & 4 & 5 & 6 \\
\hline White British (per cent) & 94.35 & 67.65 & 25.14 & 26.80 & 41.62 & 41.55 \\
\hline Born in Eastern Europe (per cent) & 0.25 & 1.19 & .71 & 0.61 & 2.57 & 1.32 \\
\hline Asian Indian (per cent) & 0.72 & 5.66 & 49.28 & 5.22 & 3.53 & 18.66 \\
\hline Pakistani and Bangladeshi (per cent) & 0.45 & 4.98 & 7.65 & 50.23 & 5.08 & 11.89 \\
\hline Black (per cent) & 0.56 & 6.41 & 5.96 & 6.49 & 27.82 & 9.98 \\
\hline Average Simpson's diversity index & 1.62 & 13.88 & 24.57 & 28.45 & 28.93 & 37.12 \\
\hline Number of MSOAs & 936 & 291 & 27 & 34 & 105 & 99 \\
\hline
\end{tabular}




\section{Individual Level Determinants of Social Cohesion}

To mitigate claims of 'ecological fallacy' we need to control for possible individual characteristics, which may influence social capital and cohesion. Following previous studies we control for occupation and education level, employment, income, the residential status of an individual (council tenancy, housing association tenancy, and private renting, compared with owning a home), length of time lived in the neighbourhood and whether one was born in the United Kingdom. (Hall, 1999; Li et al., 2005; Soroka, et al., 2005; Putnam, 2007).

We control for an individual's ethnicity by analysing the effect of being Other White, Indian, Pakistani and Bangladeshi, Black Caribbean, Black African, Mixed Race, Chinese, and Other, compared to being White British. We also control for religion by examining the effect of being Hindu, Muslim, Sikh, Christian, and 'other religion' (including Buddhists, Jews, and those with 'any other religion'), compared to being affiliated with no religion.

Furthermore, we look at the effect of increasing age, and being female compared to being male (Putnam 2000; Stolle 2001). Table 2 shows the means, standard deviations, minimum and maximum values, reference groups of categorical variables, and number of observations.

\section{Method}

To analyse the effect of individual and community level drivers of social cohesion this article employs random-intercept hierarchical linear models. We use a two-stage modelling technique to more fully explore the relationship between diversity and disadvantage. The structure of this article will therefore be as follows: first, we will model the effect of community level diversity using the Simpson Reciprocal Index of Diversity on social capital (excluding our disadvantage indicators) whilst controlling for all individual level characteristics and residential turnover. Secondly, we will model the effect of our index of diversity whilst controlling for community level disadvantage (to isolate the relative importance of disadvantage). We will repeat this process for our second measure of cohesion: tolerance to diversity. To explore whether different ethnic groups and different ethnic mixes in a community affect our social cohesion indicators differently we will repeat the above analysis but replace the index of diversity with our area typology.

\section{Results}

\section{What is the Effect of Community Disadvantage and Ethnic Diversity on Social Cohesion?}

In terms of the individual level controls, on the whole, lower socioeconomic status (education, income, occupation, non-homeownership, unemployment) predicts lower 'social capital'. When we add in community level disadvantage in model 2 the only change is that income is no longer significant. All these individual level patterns are well established from past research. The effects of individual level characteristics on reported levels of 'tolerance' tend to mirror their effects on social capital i.e. that experiencing more disadvantage leads to lower reported tolerance. However, income, unemployed status, and private renting tenancies do not have a significant effect on reported levels of tolerance. That individual measures of disadvantage are less significant in predicting tolerance (compared to social capital) may reflect that for interethnic relations 'relative disadvantage' is more important than 'absolute disadvantage'. The significance of these variables does not change with the addition of community level disadvantage.

We now turn to the effects of community level diversity and disadvantage. Table 3 shows only the effects of our 'community level' variables on social capital and tolerance (although all individual level controls included in the models, even though their coefficients are not be displayed).

Using the Simpson Reciprocal Index of Diversity we observe that as the level of ethnic heterogeneity increases, reported levels of social capital in a community decrease (model 1). As expected, community disadvantage also has a significant negative effect on social capital (model 2). Importantly, controlling for disadvantage approximately halves the pejorative effect of ethnic diversity; however, diversity continues to exert a negative effect on social capital. We can also see that as the rate of residential turnover increases, reported levels of social capital also decrease.

Repeating this test for tolerance we find that rising community diversity has a positive but nonsignificant effect on levels of tolerance. However, when we control for community level disadvantage, diversity now has a significant positive effect on tolerance to diversity while disadvantage has a significant negative effect. As well as now rendering diversity significant, controlling for disadvantage also more than doubles the positive effect of living in a diverse community. 
Table 2 Descriptive statistics for variables analysing reported 'social capital' and 'relations between ethnic groups'

Mean $\begin{gathered}\text { Standard Minimum Maximum Observations } \\ \text { deviation }\end{gathered}$

\begin{tabular}{|c|c|c|c|c|c|}
\hline \multicolumn{6}{|l|}{ Dependent variables } \\
\hline Social capital (factor) & 0.00 & 1.00 & -1.97 & 3.85 & 10587 \\
\hline $\begin{array}{l}\text { Relations between ethnic groups } \\
\text { (factor) }\end{array}$ & 0.00 & 1.00 & -2.34 & 1.29 & $920 s$ \\
\hline Trust & 3.19 & 0.81 & 1 & 4 & 11080 \\
\hline \multicolumn{6}{|l|}{ Individual level independent variables } \\
\hline Income (categories) & 4.89 & 3.28 & 1 & 14 & 13206 \\
\hline Age & 46.61 & 18.04 & 16 & 100 & 13555 \\
\hline Qualifications (categories) & 3.6 & 1.87 & 0 & 6 & 11706 \\
\hline $\begin{array}{l}\text { Upper occupations (ref: lower } \\
\text { occupations) }\end{array}$ & 0.57 & 0.5 & 0 & 1 & 12994 \\
\hline Years lived in neighbourhood & 16.28 & 15.75 & 0 & 91 & 13539 \\
\hline Not UK born (ref: UK born) & 0.3 & 0.46 & 0 & 1 & 13530 \\
\hline Unemployed (ref: employed) & 0.03 & 0.18 & 0 & 1 & 13164 \\
\hline Council tenancy (ref: owner) & 0.13 & 0.34 & 0 & 1 & 13008 \\
\hline $\begin{array}{l}\text { Housing association tenancy (ref: } \\
\text { owner) }\end{array}$ & 0.09 & 0.28 & 0 & 1 & 13008 \\
\hline Private renting (ref: owner) & 0.1 & 0.3 & 0 & 1 & 13008 \\
\hline Female (ref: male) & 0.55 & 0.5 & 0 & 1 & 13555 \\
\hline White other (ref: White British) & 0.03 & 0.17 & 0 & 1 & 13549 \\
\hline Mixed (ref: White British) & 0.04 & 0.18 & 0 & 1 & 13549 \\
\hline Indian (ref: White British) & 0.1 & 0.3 & 0 & 1 & 13549 \\
\hline $\begin{array}{l}\text { Pakistani and Bangladeshi (ref: } \\
\text { White British) }\end{array}$ & 0.07 & 0.25 & 0 & 1 & 13549 \\
\hline Asian other (ref: White British) & 0.02 & 0.14 & 0 & 1 & $1354 \mathrm{c}$ \\
\hline $\begin{array}{l}\text { Black Caribbean (ref: White } \\
\text { British) }\end{array}$ & 0.06 & 0.24 & 0 & 1 & 13549 \\
\hline Black African (ref: White British) & 0.05 & 0.22 & 0 & 1 & 13549 \\
\hline Black other (ref: White British) & 0.00 & 0.05 & 0 & 1 & 13549 \\
\hline Chinese (ref: White British) & 0.01 & 0.11 & 0 & 1 & 13549 \\
\hline Other (ref: White British) & 0.03 & 0.16 & 0 & 1 & 13549 \\
\hline Hindu (ref: no religion) & 0.05 & 0.22 & 0 & 1 & 13513 \\
\hline Muslim (ref: no religion) & 0.11 & 0.31 & 0 & 1 & 13513 \\
\hline Sikh (ref: no religion) & 0.03 & 0.16 & 0 & 1 & 13513 \\
\hline Other religion (ref: no religion) & 0.04 & 0.2 & 0 & 1 & 13513 \\
\hline Christian (ref: no religion) & 0.65 & 0.48 & 0 & 1 & 13513 \\
\hline $\begin{array}{l}\text { Proportion of friends from a dif- } \\
\text { ferent ethnic group }\end{array}$ & 2.01 & 1.05 & 1 & 4 & 12272 \\
\hline $\begin{array}{l}\text { 'Perceived' proportion of area from } \\
\text { a different ethnic group }\end{array}$ & 2.47 & 1.1 & 1 & 4 & $1340 s$ \\
\hline \multicolumn{6}{|l|}{ Community level independent variables } \\
\hline Residential turnover $^{\mathrm{a}}$ & 179.1 & 59.24 & 85 & 520 & 13554 \\
\hline Simpson's diversity index ${ }^{a}$ & 10.52 & 13.74 & -6 & 63 & 13554 \\
\hline IMD $2004^{\mathrm{a}}$ & 25.57 & 14.93 & 2.3 & 75.7 & 13554 \\
\hline
\end{tabular}

Notes: ${ }^{a}$ Signifies community variable has been subjected to a small level of random noise to avoid disclosure of particular communities (this explains the minus minimum score for diversity).

Our results therefore reveal that while disadvantage operates in a similar, negative fashion on both social capital and relations between ethnic groups, diversity appears to undermine social capital but improve interethnic relations. As diversity operates differently on these two aspects on cohesion, it appears social capital and tolerance are two distinct concepts, and not necessarily co-related i.e. low social capital areas are 
Table 3 Multilevel mixed effects linear regression coefficients for the effect of the index of diversity on 'social capital' and 'tolerance to diversity', before and after controlling for disadvantage

\section{Coefficient Model 1 Model 2}

\begin{tabular}{lcc}
\hline Social capital & & \\
Residential turnover & $-0.002^{* * *}$ & $-0.001^{* * *}$ \\
Simpson's diversity index & $-0.01^{* * *}$ & $-0.006^{* * *}$ \\
IMD 2004 & - & $-0.012^{* * *}$ \\
Between MSOA variance & 0.27 & 0.23 \\
Within MSOA variance & 0.88 & 0.87 \\
Adjusted $R^{2}$ & 0.14 & 0.16 \\
$N$ & 7706 & 7706 \\
\hline & Model 3 & Model 4 \\
\hline Tolerance to diversity & & \\
Residential turnover & 0.000 & $0.001^{* *}$ \\
Simpson's diversity index & 0.001 & $0.003^{* * *}$ \\
IMD 2004 & - & $-0.007^{* * *}$ \\
Between MSOA variance & 0.19 & 0.17 \\
Within MSOA variance & 0.66 & 0.66 \\
Adjusted $R^{2}$ & 0.029 & 0.045 \\
$N$ & 6877 & 6877
\end{tabular}

Notes: ${ }^{* * *} P<0.01 ;{ }^{* *} P<0.05 ;{ }^{*} P<0.10$; all individual level controls were included in the model estimation but we have not displayed their coefficients.

not necessarily characterised by low tolerance to diversity.

\section{Does the Impact of Diversity Depend on the Ethnic Structure of the Community?}

To explore whether the effect of diversity on social cohesion is dependent on the structure of diversity in a community we remodelled our data but used our diversity area typology (with 'Predominantly White British' as the excluded baseline area type). Table 4 shows that similar to our diversity index, compared to living in a predominantly homogeneous White British area, all area clusters have a significant negative effect on social capital. However, when we control for disadvantage, 'substantial Indian' and 'substantial Pakistani and Bangladeshi' areas are no longer significant. In other words, there is no significant difference in reported levels of social capital for individuals living in 'substantial Indian' or 'substantial Pakistani and Bangladeshi' areas compared to those living in a 'predominantly White British' area.

When we test for the effect of our diversity clusters on 'tolerance to diversity' we find that only 'substantial Indian' areas have a significantly positive effect on
Table 4 Multilevel mixed effects linear regression coefficients for the effect of the diversity area clusters on 'social capital' and 'tolerance to diversity', before and after controlling for disadvantage

\section{Coefficient \\ Model $1 \quad$ Model 2}

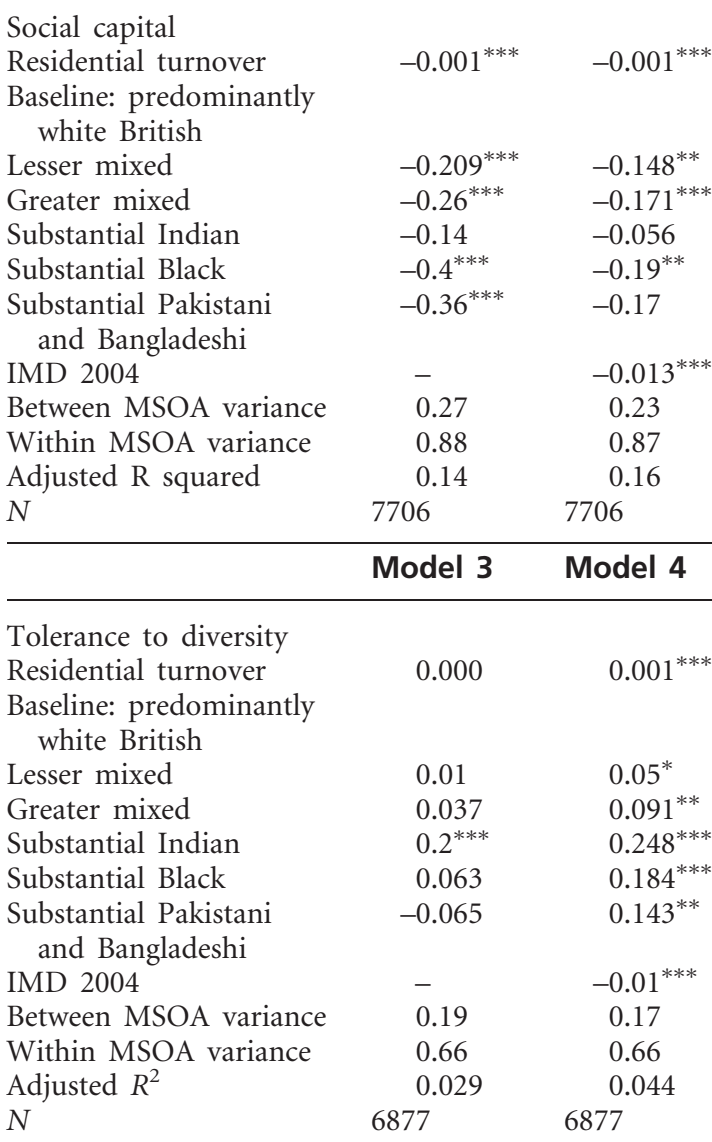

Notes: ${ }^{* * *} P<0.01 ;{ }^{* *} P<0.05 ;{ }^{*} P<0.10$; all individual level controls were included in the model estimation but we have not displayed their coefficients.

reported levels of tolerance compared to living in a predominantly homogeneous 'White British' area. However, when we control for disadvantage, living in any type of area has a significant, positive effect on levels of tolerance compared to living in a 'predominantly White British area' (although living in a 'substantial Pakistani and Bangladeshi area' is significant only to a 0.1 significance level). This indicates that for the most part all types of diverse areas improve tolerance compared to 'predominantly homogeneous 
White British' areas, which is similar to our findings using the single diversity index.

Disaggregating diversity therefore suggests that the effect of diversity on an individual's social capital may be partially dependent on the 'ethnic structure' of the community the individual inhabits. Do our findings fit a consistent pattern in terms of the possible mechanisms we proposed may link different structures of diversity to differential impacts on social capital?

First, that both these areas are ethnically bifurcated may suggest that such communities do not experience the eroding effect of diversity on social ties as strongly as mixed areas. However, we would expect 'substantial black' areas to also exhibit no significant difference in reported levels of social capital (which they do not). Secondly, considering the current levels of tension between the white British and Muslim (predominantly Pakistani and Bangladeshi) communities in the United Kingdom it seems unlikely that the lack of a significant difference is a consequence of warmer relations between these groups (Flint and Robinson, 2008). The final possibility is that if it is true that people prefer to interact with those similar to themselves ('homophily'), areas with a large stock of one's own ethnic group may exhibit higher levels of social capital than those without. Looking at Table 1, compared to 'substantial black' areas, where the mean size of the black population is around 28 per cent, in 'substantial Indian' areas and 'substantial Pakistani and Bangladeshi' areas the mean is approximately 50 per cent. Therefore, the greater ethnic homogeneity in these areas is perhaps maintaining higher levels of social capital. However, if this were the case we may expect that 'lesser mixed' areas would also exhibit no significant difference as the mean proportion of whites in these areas is 68 per cent, yet these areas report less social capital than 'predominantly white British' areas.

The lack of consistency across any one interpretation prohibits us from claiming the likelihood of one scenario over another. However, if we observe the confidence intervals for the area types we find a substantial amount of crossover, of which we should be cautious (Brown, 1968), suggesting the need to test whether for social capital, 'substantial Indian' and 'substantial Pakistani and Bangladeshi' areas are not only 'not' significantly different from 'predominantly White British' areas, but also whether they are significantly different from the remaining types of diverse areas ${ }^{8}$. When we do this we find that for social capital, while 'substantial Indian' and 'substantial Pakistani and Bangladeshi' areas were not significantly different from 'predominantly homogeneous White British' areas, neither were they consistently significantly different from the remaining diverse area types (while 'White homogeneous British' areas were). There are also fewer 'substantial Indian' and 'substantial Pakistani and Bangladeshi' areas (27 and 34 communities, respectively) compared to our other area types (Table 1). The confidence intervals for these dummy variables are therefore understandably larger, which also means we should be more cautious about the lack of significance.

In sum, our results demonstrate that while some differences may exist between different types of community ethnic structure, the lack of consistent statistical differences, the smaller sample size of 'substantial Indian' and 'substantial Pakistani and Bangladeshi' areas, and minimal (or negative) changes in the strength of the model fit (r-squared values), make it difficult to claim these differences to be robust. At least in the context of this study, using a single diversity index is a superior measure of diversity, producing a better fit and a more robust model. However, our results do suggest more attention may need to be paid to different community structures of diversity in future work.

\section{What mediates the Effect of Community Ethnic Diversity on Social Cohesion?}

Our results have so far demonstrated that increasing diversity at the community level is associated with lower reported social capital, but higher reported tolerance, at the individual level. We originally hypothesized that such results would reflect the idea that while increasing diversity undermines absolute rates of social interaction and network interconnectedness in a community (thus leading to lower levels of social capital), at the same time it increases the likelihood of interethnic contact (therefore increasing tolerance). We are unable to explicitly test these predictions as the 2005 UK Citizenship Survey does not have data on the level (and ethnic make-up) of neighbourhood interaction. However, we do have a variable which captures the ethnic make-up of an individual's social network: "what proportion of your friends is from the same ethnic group as you: 'all the same', 'more than half, 'about half, or 'less than half?" Based on how we believe diversity affects individual social cohesion outcomes, we can make several predictions regarding how including this variable might affect the coefficient of diversity on social capital and tolerance.

The first claim is that part of why increasing diversity leads to greater tolerance is that rising heterogeneity increases the likelihood of interethnic contact (and the possibility of the establishment of 
'bridging' ties), which in turn improves interethnic relations. An observation that the size of the positive effect of diversity on tolerance is reduced when we control for the presence of 'bridging ties' would provide some evidence that this is the case. However, it may be that the positive effect of diversity is actually 'dependent' on 'bridging' ties; therefore we will also include an interaction term between the two variables.

In terms of the relationship between social capital and diversity, if it is the case that rising ethnic diversity undermines the absolute frequency of social connections between community members (and thus lowers social capital), we would expect that those individuals who form interethnic ties in diverse environments will not experience the negative effect of diversity as powerfully as those who form no 'bridging' ties. One method of testing this would be to observe whether the negative effect of diversity increases when we also control for 'bridging ties'; in other words, whether those who form 'bridging' ties in diverse environments do not feel the negative effect of diversity as strongly, leading to, at present, an underestimation of diversity's negative effect. Again, we will also experiment with an interaction term between the two variables.

To test these claims we will use a binary measure of 'bridging' and 'bonding' social capital, comparing the effect of the presence of 'bridging' ties within one's network to those individuals with no 'bridging' ties. This is done to minimize problems caused by the original variable's setting of a zero-sum relationship between levels of bridging and bonding social capital ${ }^{9}$. Secondly, in moving on to explore the mechanisms which translate diversity into individual social capital outcomes we will restrict our analysis to social trust ('how far can people in your neighbourhood be trusted?'). At the centre of trust building is interaction and therefore trust is likely to be the most responsive social capital variable to differences in an individual's patterns of community interaction (Marschall and Stolle, 2004). In our own study trust is the most sensitive social capital indicator to changes in both diversity and disadvantage ${ }^{10}$. Also, trust is the most frequently used instrument in the measurement of social capital in other diversity studies and will therefore allow for more robust comparisons with other research.

\section{Diversity and the Role of 'Bridging' Ties}

Model 1 (in Table 5) is a replication of model 2 (in Table 3), only this analysis uses social trust as our measure of social capital. We can see that the basic relationships are still present: that both increasing ethnic diversity and disadvantage undermine an individual's stock of social capital (as measured by social trust) in their neighbourhood ${ }^{11}$.

In model 2 we add in our 'bridging' ties variable. In controlling for the presence of 'bridging' ties in one's social network the effect of diversity increases by approximately 6 per cent. This suggests the magnitude of diversity's effect in model 1 was kept artificially low, and that once we control out the role of 'bridging' ties diversity has a larger pejorative impact on trust in one's neighbours. To formally explore this, in model 3 we include an interaction term between 'bridging' ties and ethnic diversity. We can see the coefficient is positive and significant (to a 0.05 level). At the same time, diversity continues to have a significant negative effect (to a 0.001 level).

These results suggest that amongst all individuals (regardless of the make-up of their social network) higher diversity is associated with less trust in neighbours. However, amongst those whose social networks contain 'bridging' ties diversity has a significantly weaker effect compared to those whose networks contain only 'bonding' ties.

We move now to tolerance. Model 5 (in Table 5) replicates the analysis of model 4 (in Table 3), in which increasing diversity has a positive effect on tolerance to diversity and increasing disadvantage has a negative effect. In model 6 we control for 'bridging' ties. Firstly, the effect of 'bridging' ties is significant, suggesting individuals with 'bridging' ties report significantly greater levels of tolerance than those with none. Furthermore, controlling for 'bridging' ties reduces the effect of diversity by around 10 per cent (although diversity remains positive and significant). This suggests that part of why diversity has a positive effect on an individual's reported tolerance to diversity is the association between increasing diversity and 'bridging' ties.

In model 7 we formally test the relationship between 'bridging' ties and diversity by adding in an interaction term between the variables. Similar to the relationship between 'bridging' ties, diversity and trust, the coefficient is positive and significant, but now the effect of diversity is nonsignificant. This suggests that the positive effect of increasing diversity on tolerance is dependent on the relationship between diversity and 'bridging' ties, and in networks with none diversity has no positive effect ${ }^{12}$.

'Bridging' ties therefore play an important role in the effect of diversity on trust and tolerance. That controlling for 'bridging' ties without accounting for their interactive effect with diversity has only a small mediating effect on our measures of social cohesion 
Table 5 Multilevel mixed effects linear regression coefficients for the effect of diversity, and the mediating effect of 'bridging' ties, on 'social capital' and 'tolerance to diversity'

Trust

Tolerance to diversity

Model 1 Model 2 Model 3 Model $4^{\text {a }}$ Model 5 Model 6 Model 7 Model $8^{\text {a }}$

\begin{tabular}{|c|c|c|c|c|c|c|c|c|}
\hline Residential turnover & $-0.0004^{* * *}$ & $-0.0005^{* * *}$ & $-0.0005^{* * *}$ & $-0.0006^{* * *}$ & $0.0004^{* *}$ & $0.0004^{* *}$ & $0.0004^{* *}$ & $-0.0006^{* * *}$ \\
\hline $\begin{array}{l}\text { Simpson's diversity } \\
\text { Index/self-perceived } \\
\text { diversity }\end{array}$ & $-0.0056^{* * *}$ & $-0.0059^{* * *}$ & $-0.009^{* * *}$ & $-0.096^{* * *}$ & $0.0039^{* * *}$ & $0.0035^{* * *}$ & 0.001 & $-.014^{* * *}$ \\
\hline IMD 2004 & $-0.01^{* * *}$ & $-0.01^{* * *}$ & $-0.01^{* * *}$ & $-0.01^{* * *}$ & $-0.007^{* * *}$ & $-0.007^{* * *}$ & $-0.007^{* * *}$ & $-0.007^{* * *}$ \\
\hline 'Bridging ties' & & 0.035 & 0.008 & -0.028 & & $0.064^{* * *}$ & 0.037 & -0.051 \\
\hline 'Diversity' $\times$ 'Bridging' ties & & & $0.004^{* *}$ & $0.047^{* *}$ & & & $0.004^{* *}$ & $0.053^{* *}$ \\
\hline Between MSOA variance & 0.17 & 0.17 & 0.17 & 0.17 & 0.16 & 0.16 & 0.16 & 0.16 \\
\hline Within MSOA variance & 0.70 & 0.70 & 0.70 & 0.70 & 0.66 & 0.66 & 0.66 & 0.65 \\
\hline Adjusted $R^{2}$ & 0.18 & 0.18 & 0.19 & 0.19 & 0.047 & 0.048 & 0.05 & 0.057 \\
\hline$N$ & 8704 & 8704 & 8704 & 8666 & 6486 & 6486 & 6486 & 6487 \\
\hline $\begin{array}{l}\text { Change in effect of } \\
\text { diversity (per cent) }\end{array}$ & & 6 & & & & -10 & & \\
\hline
\end{tabular}

Notes: ${ }^{* * *} P<0.01 ;{ }^{* *} P<0.05 ;{ }^{*} P<0.10$; all individual level controls were included in the model estimation but we have not displayed their coefficients. ${ }^{a}$ Diversity measure used in the model is 'proportion of individual's area that is one's own ethnic group (perception)'.

(around 8 per cent each) is partly because the role of 'bridging' ties is, in part, 'dependent' on the level of diversity as demonstrated by the significant interaction terms. To better understand the implications of our results we will visualize the core relationships. Following Stolle et al. (2008) we use predicted scores of our social cohesion measures.

Figure 1 summarizes the effect of diversity on trust amongst those with, and those without, 'bridging' ties (scores based on Table 5, model 4). First, we see that increasing diversity has a negative impact on all individuals' reported levels of localized trust (whether there are 'bridging' ties present or not). However, this effect is significantly weaker amongst individuals with 'bridging' social ties. The presence of 'bridging' ties in one's network therefore serve as an effective buffer, mitigating the detrimental impact of increasing diversity on trust.

Figure 2 summarizes the relationship between diversity and tolerance (based on model 8). Importantly, the effect of diversity on tolerance depends on whether an individual has 'bridging' ties in their social networks. Amongst those that do, increasing diversity leads to a significant increase in tolerance. However, amongst those without 'bridging' ties, increasing diversity has no significant effect on levels of 'tolerance' to diversity (although the relationship is positive).

These findings are very important as they suggest 'bridging' ties not only play a vital role in mediating the pejorative effect of diversity on trust in a community, but also that it is the association between 'bridging' ties and diversity that leads to improved attitudes of tolerance with rising diversity. However, for such claims we want to more rigorously test these findings.

\section{Social Cohesion and Self-Perceived Diversity}

Up until this point we have been looking at the effect of the census-based level of ethnic diversity. However, the 2005 Citizenship Survey also contains a measure of an individual's 'perception' of the relative size of their ethnic group in their neighbourhood: 'Thinking about people in this local area (15/20 minutes walking distance), what proportion of all the people are of the same ethnic group as you: "All the same", "more than a half", "about a half", or "less than a half"?

First, this 'perception' variable is less a measure of how ethnically diverse an area is (the probability that two randomly selected individuals in the community will be from the same ethnic group), but more a measure of the perception of the concentration of one's own group in one's locale. As Table 1 shows for example, 'Substantial Black' areas have a mean 'White British' population of 42 per cent while 'Substantial Pakistani and Bangladeshi' areas have a mean 'White British' population of 26 per cent. However, the areas have almost identical Diversity Index scores due to the proportions of other ethnic groups in the area. Secondly, as this variable is an individual's own 'perception' of the ethnic make-up of their neighborhood, it should capture the relative exposure (and not simply the census-based proximity) of an 


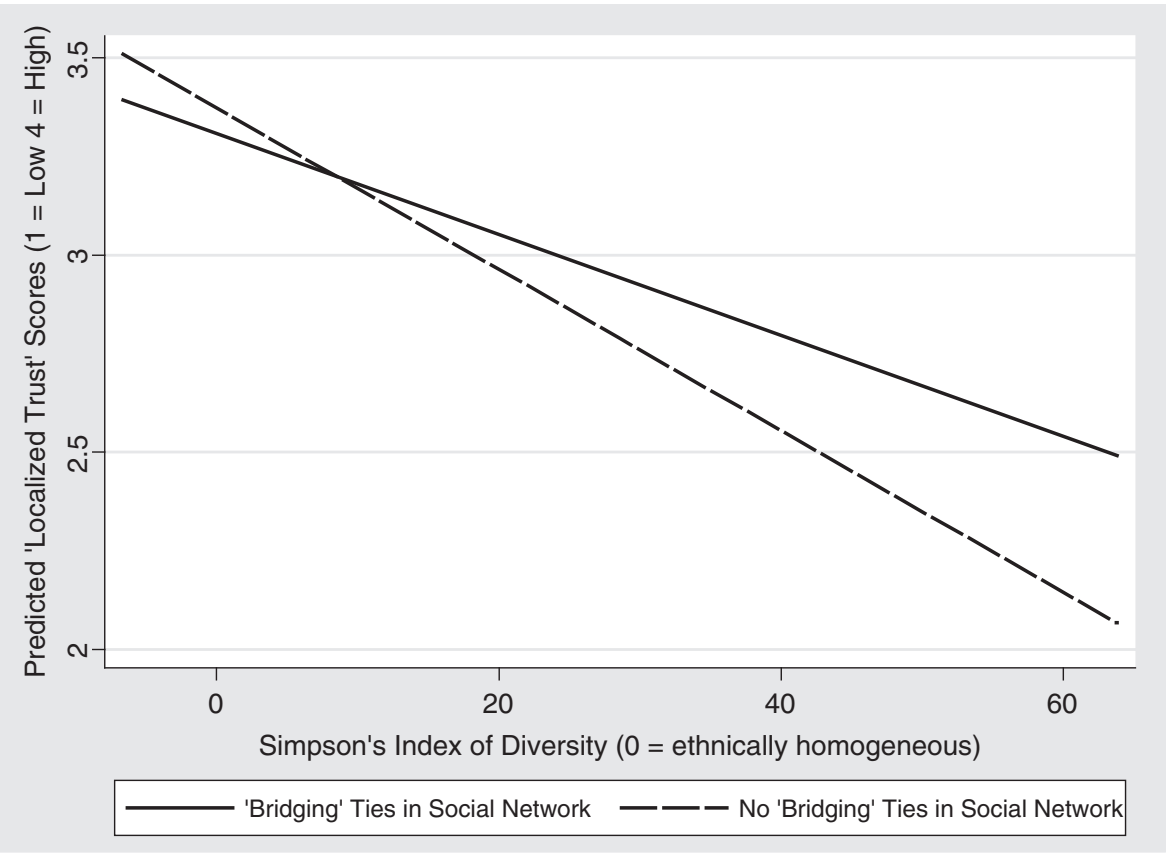

Figure 1 Predicted 'Localised Trust' scores of individuals with 'bridging' ties and individuals without 'bridging' ties. Notes: Scores below zero are a consequence of the small level of random noise added to the 2001 Census population data.

individual to ethnic groups other than their own in their immediate area (Stolle, 2008). Using this variable we can further explore whether 'bridging' ties reduce the negative effect of 'perceiving' that one has a smaller pool of one's own ethnic group to interact with, and also whether 'bridging' ties continue to foster attitudes of tolerance even as an individual increasingly sees themselves in the minority in their neighborhood.

Models 4 and 8 replicate models 3 and 7 but substitute the Simpson Reciprocal Index of Diversity for an individual's perception of the proportion of their neighbourhood that is of their own ethnic group. We find that for localized trust, the more an individual perceives their own ethnic group is in a minority in an area, the lower their reported levels of trust. However, once more, we find diversity has a significant, positive interaction with the presence of 'bridging' ties in one's social network. For tolerance to diversity, contrary to our findings in model 7, those with no 'bridging' ties in their social network exhibit a small but significant decrease in tolerance as they perceive their own ethnic group to make-up an increasingly smaller proportion of their neighbourhood. However, akin to model 7 and census-based diversity, the interaction term between self-perceived diversity and 'bridging' ties is positive and significant.

That 'bridging' ties play a similar role as the perceived proportion of one's area becomes increasingly ethnically dissimilar is further evidence that our findings on 'bridging' ties are robust. Their importance for social cohesion is, if anything, increased, as we identify a small but significant negative effect on tolerance amongst those with no 'bridging' ties, but a positive interaction term between diversity and those with 'bridging' ties. These results therefore add evidence towards the understanding of the mechanisms linking community level diversity with individual level social cohesion outcomes. However, before we move on to interpret these findings in the context of our proposed mechanisms there are a number of statistical issues we must contend with to bolster our confidence in the findings.

\section{Statistical Caveats}

First, we're assuming that at least part of our measure of 'bridging' ties is capturing interethnic ties formed 


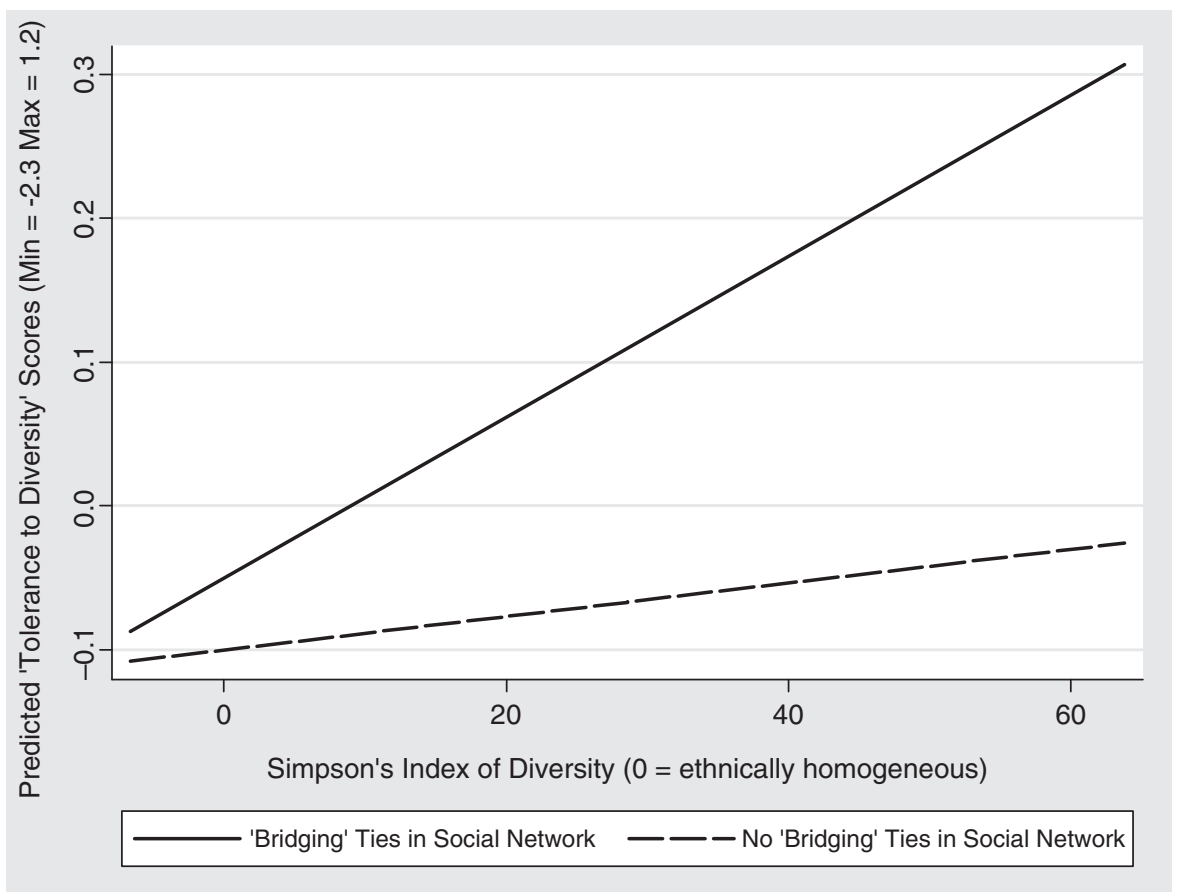

Figure 2 Predicted 'Tolerance to Diversity' scores of individuals with 'bridging' ties and individuals without 'bridging' ties. Notes: Scores below zero are a consequence of the small level of random noise added to the 2001 Census population data.

in one's neighbourhood (as a consequence of living in a diverse community). However, the variable itself does not specify the location of the tie. If we formally model the likelihood of having 'bridging' ties we find that increasing diversity significantly predicts an increasing likelihood of having 'bridging' ties (to a 0.001 significance level), even with full individual and community level controls (we discuss the potential that this is a result of self-selection below).

Another caveat is that our measure of 'tolerance to diversity' is measuring the individual's perception of the level of prejudice/tolerance in others in their community (not their own prejudice), and therefore does not accurately capture the individual's own level of prejudice. However, these types of 'perception of your neighbours in the wider community' questions often form part of measures of social capital (Lochner et al., 2001; Li et al., 2005; Letki, 2008). Our 'relations between ethnic groups' questions similarly attempt to capture the state of social relations between different ethnic groups, and the level of prejudice, within a community. Considering these are measures of an individual's perception of those in their locale (and not of their own prejudice), they may also be less susceptible to 'social desirability' bias.

Thirdly, potentially the results are the product of 'selection issues'. In reference to trust, a selection effects interpretation would require "that when nonwhites move into a previously all-white neighbourhood, the first whites to flee (or the most reluctant to move in) would be the most trusting, and the last to flee would be the least trusting" (Putnam 2007; p. 153). However, in terms of interethnic relations, one possibility is that less tolerant individuals selfselect into more similar ethnically homogeneous communities (Clark, 1992; Zubrinsky et al., 1996). As an approximate test for this we examined whether there were differences in the effect of diversity on different socioeconomic classes (used as a proxy for the ability of an individual to be choose where to live $)^{13}$. Social class and affluence are often recommended as proxies for ability to select areas of residence (Majka and Donnelley, 1998; MacAllister et al., 2001).

The results show that diversity has a positive effect on the tolerance of those individuals who (in theory) 
have more choice in which communities they choose to reside, while diversity has no significant effect on tolerance for those with less choice. This provides some preliminary evidence that perhaps the positive relationship between ethnic heterogeneity and positive views of other ethnic groups may be caused selfselection where those who can't self-select into (or out of) diverse environs experience no significant positive effect on tolerance. Alternatively, we may be picking up differences in how low status groups respond to exposure to other ethnic groups (Rothgerber and Worchel, 1997; Klandermans and De Weerd, 2000; Verkuyten and Reijerse, 2008).

\section{Discussion and Conclusion}

This article confirms the increasingly ubiquitous finding that rising ethnic diversity in a community is associated with lower reported levels of social capital. However, it also shows that while an individual living in a diverse environment may report lower levels of social capital 'the same individual' is also likely to have more positive interethnic relations.

We hypothesized that part of what links community level diversity to these differential individual-level social cohesion outcomes is diversity's impact on interaction and the interconnectedness (and ethnic makeup) of one's social network. Our finding that individuals with 'bridging' ties in their social networks experiences the effect of rising diversity increasingly less negatively compared to those without ${ }^{14}$ provides some evidence to support the position that diversity erodes interconnectedness and the level of interaction between community members, as it is those who have no 'bridging' ties (who are therefore less likely to be connected in a diverse community) that experience the lowest level of social capital.

We also observed that those with 'bridging' ties (the presence of which increase with increasing diversity) also report greater tolerance as diversity increases, while diversity has no effect amongst those individuals with no 'bridging' ties (or in the case of increasingly perceiving one's ethnic group to be in the minority in an area, a lack of 'bridging' ties actually leads to lower tolerance). This provides evidence for our claim that rising diversity increases tolerance by leading to more exposure to other ethnic groups, and an increasing likelihood of forming 'bridging' ties.

Our results also suggest diversity in the United Kingdom may have a different effect on social cohesion compared to the U.S. Putnam (2007) found that increasing heterogeneity is associated with both low bridging and low bonding capital (as measured by intra- and interethnic trust), or a 'hunkering down'. In our study, diversity does appear to undermine social capital and interconnectedness in a community; however, relative to more homogeneous areas, diversity is also associated with better interethnic relations suggesting it does not necessarily lead to social isolation between an area's inhabitants ('hunkering') but can foster interethnic interaction and 'bridging' capital. Disadvantage on the other hand not only undermines community connectedness more strongly (it has a negative effect on social capital twice as powerful as that of diversity), but is also simultaneously associated with worse interethnic relations. Its effect in the United Kingdom appears much more symptomatic of 'hunkering' than diversity.

From a policy perspective, simply using social capital to measure social cohesion can generate a prematurely negative picture of the relationship between diversity and cohesion, and sideline the potential benefits at both the community and societal level of greater tolerance to diversity. Also, that diversity operates differently on social capital and tolerance demonstrates that 'social cohesion' is a multifaceted concept and much closer attention needs to be paid to better capture its multidimensionality before claims can be made on its 'decline' in relation to diversity. Furthermore, our finding on the positive role of 'bridging' ties in social cohesion suggests that policies that encourage the growth of social capital (especially 'bridging' social capital) in diverse areas (for example, creating opportunities and incentives for formal volunteering, involvement in local civil renewal activities, informal volunteering ${ }^{15}$ ) could play a vital role in fostering both trust and tolerance.

Secondly, our results clearly demonstrate that attention must be paid to disadvantage in both definitions of, and policy initiatives to encourage, social cohesion. While diversity does play a role in weakening social capital, there are significant benefits to the weakening of in-group boundaries and the encouragement of a super-ordinate identity. Disadvantage on the other hand not only has a much stronger eroding effect on social capital than diversity, but is also associated with increasing intolerance. In fact, it is only when we control out disadvantage's negative effect that diversity significantly improves tolerance. Any truly concerted effort to tackle problems of community tensions must take this into account and not relegate the role of disadvantage at the expense of simply attempting to encourage greater community interaction. 


\section{Notes}

1. The 2008 BSA has not yet been made public and analysis was done with special licence from the Office for National Statistics.

2. Analysing the effect of community demographics in 2001 (or 2004 in the case of disadvantage) on an individual's attitudinal outcomes in 2005 is not ideal; however, 2001 is the closest year for which accurate data is available on the level of ethnic diversity at a small enough scale to be representative of an individual's community (MSOA), and 2004 is the closest year for which we have indices of disadvantage available at the same scale of analysis.

3. There is the possibility that individuals may interpret the term 'different backgrounds' differently (ethnic, socioeconomic, etc.). However, the Cronbach's alpha for this question and the 'respect for ethnic differences' question was suitably high $(0.67)$ to suggest they were measuring the same underlying concept.

4. We also tested whether the questions measuring social capital and tolerance of other ethnic groups all load on to one factor of 'social cohesion'. However, the factor analysis consistently returned two distinct factors.

5. This is not ideal as important differences do exist in terms of levels of residential segregation. However, the many sociocultural similarities theoretically may mean they are perceived similarly by other groups.

6. These areas fit our theoretical predictions of a division of communities into mixed versus bifurcated areas and how bifurcated areas can be further divided by the type of ethnic population which resides within. However, white-black bifurcated areas contain on average a smaller concentration of black people and larger concentration of white British people than Indian or Pakistani and Bangladeshi bifurcated areas, which we need to keep in mind.

7. The 2004 Index of Multiple Deprivation is an area level aggregation of seven dimensions of disadvantage generated, in 2004, by the Office of the Deputy Prime Minister. The domains include: income, employment, health and disability, skills and training, barriers to housing and services, living environment, and crime (ODPM, 2004).
8. To do this we rearranged our dummy variables and remodelled the data to observe whether the significance of our area types changed depending on which area was the baseline category. The results showed that 'White British' areas were always significantly different from 'small mixed', 'large mixed', and 'substantial Black' areas, regardless of the baseline category. However, while 'substantial Indian' and 'substantial Pakistani and Bangladeshi' areas were not significantly different from 'White British' areas, neither were they consistently significantly different from other types of area.

9. The artificial creation of a zero sum relationship between bridging and bonding social capital means we cannot treat higher proportions of friends from a different ethnic group as an indicator of greater absolute levels of 'bridging' ties. For example, an individual with three friends, two of which are from another ethnic group would report that 'over half of their friends are from a different ethnic group to themselves', while an individual with 10 friends, 5 of which are from another ethnic group, would only report that 'half of their friends are from a different ethnic group to themselves'. Using the original measure of 'bridging', the individual with the larger absolute number of 'bridging' ties would receive a lower value than the individual with less.

10. Trust in one's neighbours is more strongly correlated (over 10 points higher) with disadvantage and ethnic diversity than any other social capital indicator and is also more sensitive to individual level indicators of disadvantage. Trust also correlates more strongly with the remaining social capital measurements than they do with one another.

11. The same relationship that exists for trust also exists for our social capital index, although as expected the effect and significances are slightly weaker.

12. Testing for the presence of multicolliniarity, the variance inflation factors scores for the interaction variables themselves are 4.4 and 4.8, respectively. Furthermore, we ran our data through 'generalized linear latent and mixed models' with 'robust standard errors' and neither of our interaction terms became nonsignificant. 
13. We first divided our data set into two separate categories: upper occupations (managerial and professional, and intermediate and small employers) and lower occupations (lower supervisory and technical, and semi- and routine occupations). We then remodelled the effect of all our independent variables on these two separate groups. The results showed that while the IMD 2004 was significant for both upper and lower occupational groups, the effect of the Simpson Reciprocal Index of Diversity on tolerance did not have a significant effect on the lower occupational group (although it was positive).

14. One possibility as to why diversity still has a negative effect even for those with 'bridging' ties is that the decreasing level of engagement in the neighbourhood amongst those with no 'bridging' ties has knock effect reducing interaction for all.

15. In a full multi-level model including both community level diversity and disadvantage, engaging in formal volunteering, informal volunteering, and civil renewal projects in one's community are all independently and significantly more likely to predict having 'bridging' ties compared to those who engage in none (data not shown).

\section{Acknowledgements}

The author would like to thank Anthony Heath for his guidance and constructive comments on this project. We would like also like to thank the 'Harvard and Manchester Social Change Initiative' workshop participants for their useful comments and suggestions. Also Steven Fisher, Ceri Peach and Ludi Simpson for their help with statistical analyses, and finally Shaun Scholes at The National Centre for Social Research for his help in compiling the dataset. The author's research was undertaken while in receipt of an ESRC Award.

\section{References}

Alesina, A. and Ferrara, E. (2000). Participation in heterogeneous communities. Quarterly Journal of Economics, 115, 847-904.

Alesina, A. and Ferrara, E. (2002). Who trusts others? Journal of Public Economics, 85, 207-234.

Allport, G. W. (1954). The Nature of Prejudice. Cambridge, MA: Addison-Wesley.
Blalock, H. (1970). Estimating measurement error using multiple indicators and several points in time. American Sociological Review, 35, 101-111.

Bledsoe, T. et al. (1995). Residential context and racial solidarity among African Americans. American Journal of Political Science, 39, 434-458.

Bobo, L. (1988). Group conflict, prejudice, and the paradox of contemporary racial attitudes. In Katz, P. A. and Taylor, D. A. (Eds.), Eliminating Racism: Profiles in Controversy. NewYork: Plenum Press Books, pp. 85-114.

Brown, K. C. (1968). The significance of dummy variables in multiple regressions involving financial and economic data. Journal of Finance, 23, 515-517.

Campbell, D. T. (1965). Ethnocentric and other altruistic motives. In Levine, D. (Ed.), Nebraska Symposium on Motivation. Lincoln, NE: University of Nebraska Press, pp. 283-311.

Chan, J., To, H. P. and Chan, E. (2006). Reconsidering social cohesion: developing a definition and analytical framework for empirical research. Social Indicators Research, 75, 273-302.

Cheong, P. et al. (2007). Immigration, social cohesion and social capital: a critical review. Critical Social Policy, 27, 24-49.

Clark, W. A. V. (1992). Residential preferences and residential choices in a multiethnic context. Demography, 29, 451-466.

Commission on Integration and Cohesion (COIC) (2007). Our Shared Future: Themes, Messages, and Challenges: A Final Analysis of the Key Themes from the Commission on Integration and Cohesion Consultation. London: HMSO.

Costa, D. L. and Kahn, M. E. (2003). Civic engagement and community heterogeneity: an economist's perspective. Perspectives on Politics, 1, 103-111.

Coulthard, M., Walker, A. and Morgan, A. (2002). People's Perceptions of their Neighbourhood and Community Involvement: Results from the Social Capital Module of the General Household Survey 2000. London: The Stationery Office.

Easterly, W. and Levine, R. (1997). Africa's growth tragedy: policies and ethnic divisions. Quarterly Journal of Economics, 112, 1203-1250.

Falk, I. and Kilpatrick, S. (2000). What is social capital? A study of interaction in a rural community. Sociologia Ruralis, 40, 87-110.

Flint, J. and Robinson, D. (2008). Introduction. In Flint, J. and Robinson, D. (Eds.), Community Cohesion in Crisis?: New Dimensions of Diversity and Difference. Bristol: Policy Press, pp. 239-257. 
Forrest, R. and Kearns, A. (2001). Social cohesion, social capital and the neighbourhood. Urban Studies, 38, 2125-2143.

Forrest, J., Poulsen, M. and Johnston, R. (2003). Everywhere different? Globalisation and the impact of international migration on Sydney and Melbourne. Geoforum, 34, 499-510.

Giles, M. and Evans, A. S. (1986). The power approach to intergroup hostility. Journal of Conflict Resolution, 30, 469-486.

Gordon, M. (1964). Assimilation in American Life: The Role of Race, Religion and National Origins. New York: Oxford University Press.

Hall, P. A. (1999). Social capital in Britain. British Journal of Political Science, 29, 417-461.

Hewstone, M. et al. (2005). Intergroup contact in a divided society: challenging segregation in Northern Ireland. In Abrams, D., Marques, J. M. and Hogg, M. A. (Eds.), The Social Psychology of Inclusion and Exclusion. Philadelphia, PA: Psychology Press, pp. 265-292.

Hooghe, M. (2003). Value congruence and convergence within voluntary associations: ethnocentrism in Belgian organizations. Political Behavior, 25, 151-176.

Hooghe, M. et al. (2006). Ethnic Diversity, Trust and Ethnocentrism and Europe: A Multi-level Analysis of 21 European Countries. Paper presented at the 102nd Annual Meeting of the American Political Science Association, Philadelphia, USA, August 31-September 3, 2006.

Hornsey, M. J. and Hogg, M. A. (2000). Assimilation and diversity: an integrative model of subgroup relations. Personality and Social Psychology Review, 4, 143-156.

Jensen, J. (1998). Mapping Social Cohesion; The State of Canadian Research. Ottawa: Canadian Policy Research Network Study No. F03, available from: http://www.cprn.org/documents/15723_en.pdf.

Johnston, R., Poulsen, M. and Forrest, J. (2003). And did the walls come tumbling down? Ethnic residential segregation in four U.S. metropolitan areas 1980-2000. Urban Geography, 24, 56-81.

Kawachi, I. and Berkman, L. (2000). Social cohesion, social capital and health. In Kawachi, I. and Berkman, L. (Eds.), Social Epidemiology. Milton Keynes, UK: Open University Press, pp. 174-190.

Kearns, A. and Forrest, R. (2000). Social cohesion and multi-level urban governance. Urban Studies, 37, 995-1017.

Klandermans, B. and De Weerd, M. (2000). Group identification and political protest. In Stryker, S., Owens, T. and White, R. W. (Eds.), Self, Identity, and Social Movements. Minneapolis, MN: University of Minnesota Press, pp. 68-90.

Letki, N. (2008). Does diversity erode social cohesion? Social capital and race in British neighbourhoods. Political Studies, 56, 99-126.

LeVine, R. A. and Campbell, D. T. (1972). Ethnicentrism: Theories of Conflict, Ethnic Attitudes and Group Behaviour. New York: Wiley.

Li, Y., Pickles, A. and Savage, M. (2005). Social capital and social trust in Britain the late 1990s. European Sociological Review, 21, 109-123.

Lochner, K. et al. (2003). Social capital and neighborhood mortality rates in Chicago. Social Science and Medicine, 56, 1797-1805.

Lockwood, D. (1999). Civic integration and social cohesion. In Gough, I. and Olofsson, G. (Eds.), Capitalism and Social Cohesion: Essays on Exclusion and Integration. London: Macmillan Press, pp. 63-84.

MacAllister, I. et al. (2001). Class dealignment and the neighbourhood effect: Miller revisited. British Journal of Political Science., 31, 41-60.

Majka, J. and Donnelly, P. G. (1988). Cohesiveness within a heterogeneous urban neighborhood: implications for community in a diverse setting. Journal of Urban Affairs, 10, 141-159.

Marschall, M. J. and Stolle, D. (2004). Race in the city: neighbourhood context and the development of generalized trust. Political Behaviour, 26, 125-153.

McLaren, L. M. (2003). Anti-immigrant prejudice in Europe: contact, threat perception, and preferences for the exclusion of migrants. Social Forces, 81, 909-937.

McPherson, M., Smith-Lovin, L. and Cook, J. M. (2001). Birds of a feather: homophily in social networks. Annual Review of Sociology, 27, 415-444.

Montalvo, J. G. and Reynal-Querol, M. (2005a). Ethnic diversity and economic development. Journal of Development Economics, 76, 293-323.

Montalvo, J. G. and Reynal-Querol, M. (2005b). Ethnic polarization, potential conflict, and civil wars. American Economic Review, 95, 796-813.

Office of the Deputy Prime Minister (2004). Index of multiple deprivation 2004, http://www .communities.gov.uk.

Oliver, E. and Mendelberg, T. (2000). Reconsidering the environmental determinants of 25 racial attitudes. American Journal of Political Science, 44, 574-589.

Oliver, J. E. and Wong, J. (2003). Intergroup prejudice in multiethnic settings. American Journal of Political Science, 47, 567-582.

Pettigrew, T. F. and Tropp, L. R. (2000). Does intergroup contact reduce prejudice? Recent 
meta-analytic findings. In Oskamp, S. (Ed.), Reducing Prejudice and Discrimination: Social Psychological Perspectives. Mahwah, NJ: Erlbaum, pp. 93-114.

Pettigrew, T. F. and Tropp, L. R. (2006). A metaanalytic test of intergroup contact theory. Journal of Personality and Social Psychology, 90, 751-783.

Poulsen, M., Johnston, R. and Forrest, J. (2001). Intraurban ethnic enclaves: introducing a knowledge-based classification method. Environment and Planning A, 33, 2071-2082.

Putnam, R. D. (1993). Making Democracy Work: Civic Traditions in Modern Italy. Princeton: Princeton University Press.

Putnam, R. D. (1995). Bowling alone: America's declining social capital. Journal of Democracy, 6, 64-78.

Putnam, R. D. (2000). Bowling Alone: The Collapse and Revival of American Community. New York: Simon and Schuster.

Putnam, R. D. (2007). E Pluribus Unum: Diversity and community in the twenty-first century. The 2006 Johan Skytte Prize Lecture'. Scandinavian Political Studies., 30, 137-174.

Rawlings, L. A., Harris, L. E. and Turner, M. A. (2004). Race and Residence: Prospects for Stable Neighborhood Integration. Washington, DC: The Urban Institute.

Rex, J. and Tomlinson, S. (1979). Colonial immigrants in a British city: a class analysis. London: Routledge \& Kegan Paul.

Robinson, D. (2005). The search for community cohesion: key themes and dominant concepts of the public policy agenda. Urban Studies, 42, 1411-1428.

Rothgerber, H. and Worchel, S. (1997). The view from below: intergroup relations from the perspective of the disadvantaged group. Journal of Personality and Social Psychology, 73, 1191-1205.

Sampson, R. and Groves, W. B. (1989). Community structure and crime: testing social disorganisation theory. American Journal of Sociology, 94, 774-802.

Sampson, R., Raudenbush, S. W. and Earls, F. (1997). Neighbourhoods and violent crime: a multilevel study of collective efficacy. Science, 277, 918-924.

Sherif, M. (1966). Group Conflict and Cooperation: Their social Psychology. London: Rutledge and Kegan Paul.

Simpson, H. E. (1949). Measurement of Diversity. Nature, 163, 688.

Soroka, S., Johnston, R. and Banting, K. (2005). Ties that Bind? Cohesion and Diversity in Canada. Paper presented at the IRPP Conference Diversity and Canada's Future, Montebello, Canada, 13-15 October 2005.
Stein, R., Post, S. and Rinden, A. L. (2000). Reconciling context and contact effects on racial attitudes. Political Research Quarterly, 53, 285-303.

Stolle, D. (2001). Clubs and congregations: the benefits of joining an association. In Cook, K. (Ed.), Trust in Society. New York: Russell Sage Foundation, pp. 202-244.

Stolle, D., Soroka., S. and Johnston, R. (2008). When does diversity erode trust? Neighborhood diversity, interpersonal trust and the mediating effect of social interactions. Political Studies, 56, 57-75.

Tajfel, H. and Turner, J. C. (1979). An integrative theory of intergroup conflict. In Austin, W. G. and Worchel, S. (Eds.), The Social Psychology of Intergroup Relations. Monterey, CA: Brooks/Cole, pp. 94-109.

Taylor, M. C. (1998). Local racial/ethnic proportions and white attitudes: numbers count. American Sociological Review, 63, 56-78.

Travers, T., Tunstall, R. and Whitehead, C. (2007). Population Mobility and Service Provision: A report for London Councils. London: LSE.

Turner, M. and Fenderson, J. (2005). Understanding Diverse Neighborhoods in an Era of Demographic Change. Washington Institute: Urban Institute.

Varshney, A (2003). Ethnic Conflict and Civic Life: Hindus and Muslims, 2nd edn edition New Haven: Yale University Press.

Verkuyten, M. and Reijerse, A. (2008). Intergroup structure and identity management among ethnic minority and majority groups: the interactive effects of perceived stability, legitimacy, and permeability. European Journal of Social Psychology, 38, 106-127.

Weisberg, H (2005). The Total Survey Error Approach: A Guide to the New Science of Survey Research. Chicago: University of Chicago Press.

Woolley, F. (1998). Social Cohesion and Voluntary Activity: Making Connections. Paper presented at CSLS conference on The state of living standards and the quality of life in Canada, Canada, Ontario, 30-31 October 1998.

Zubrinsky, C. and Bobo, L. (1996). Prismatic metropolis: race and residential segregation in the city of angels. Social Science Research, 25, 335-374.

\section{Author's Address}

James Laurence, St John's College, Oxford, OX1 3JP, United Kingdom. Email: james.laurence@sjc.ox. ac.uk and james_laurence@harvard.edu

Manuscript received: January 2009 